\title{
is
}

\section{Development of Nanoparticles for Drug Delivery to the Brain}

\section{Elham Afjeh Dana ${ }^{1,2}$, Masoud Marivani ${ }^{3}$, Bita Mehravi², Fariba Karimzadeh ${ }^{4 *}$, Khadijeh Ashtari ${ }^{2 *}$}

${ }^{1}$ Cellular and Molecular Research Center, Iran University of Medical Sciences, Tehran, Iran

${ }^{2}$ Department of Medical Nanotechnology, Faculty of Advanced Technology in Medicine, Iran University of Medical Sciences, Tehran, Iran

${ }^{3}$ Department of Medical Nanotechnology, Faculty of Advanced Technology in Medicine, International Campus, Iran University of Medical Sciences, Tehran, Iran

${ }^{4}$ Shefa Neuroscience Research Center, Khatam Alanbia Hospital, Tehran, Iran

$\begin{array}{lll} & \text { Article Info: } & \\ \text { Received: } 24 \text { Oct } 2016 & \text { Revised: } 5 \text { Feb } 2017 & \text { Accepted: } 26 \text { Feb } 2017\end{array}$

\section{ABSTRACT}

Introduction: The central nervous system is one of the most sensitive microenvironments of the body that protected by the blood-brain barrier (BBB). BBB is a highly complex structure that tightly controls exchange of a range of small and large molecules, which protects the brain from damages and diseases. The promising feature of BBB in molecular movement from bloodstream into the nervous tissue affects delivery of several drugs to the brain. In order to increase drugs permeability through BBB various strategies have been developed. Among them, nanotechnology has provided effective methods for researchers in the field of drug delivery to the brain. Conclusion: In this paper, the structure and physiological properties of $\mathrm{BBB}$ as well as new strategies for drug delivery to the brain by using nanoparticles are discussed.

*Corresponding Author: Fariba Karimzadeh, Khadijeh Ashtari

E-mail: Fariba_karimzade@yahoo.com,ashtaribeh@gmail.com 
توسعة نانو ذرات در دارو رسانى به مغز

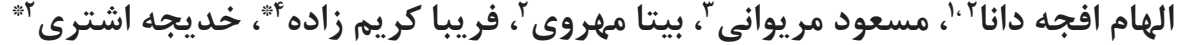 \\ 'مركز سلولى و مولكولى، دانشعاه علوم يزشكى ايران، تهران، ايران

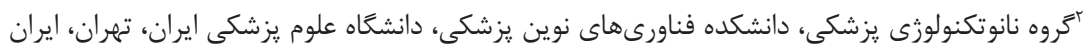

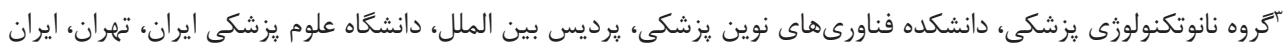

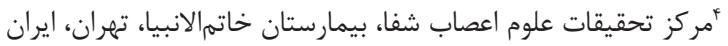

اطلاعات مقاله:

تاريخ بذيرش: 1 اسفند هوبا

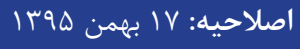

تاريخ دريافت: ب آبان هوسا

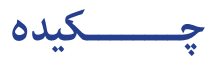

مقدمه: سيستم عصبى مركزى يكى از حساسترين محيطهاى ميكروسكويى بدن است كه توسط سد

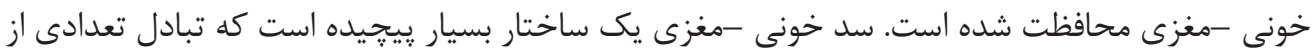

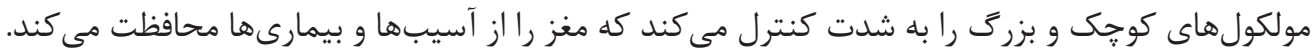

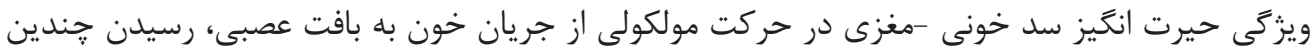

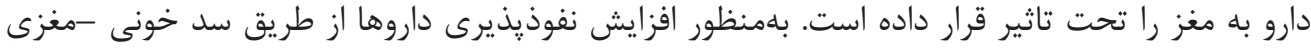

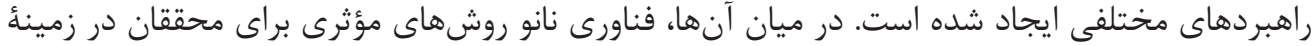

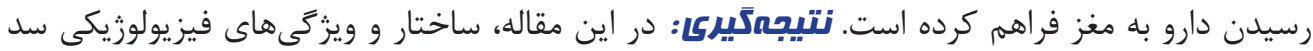

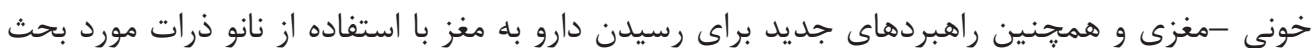
قرار گرفته است.

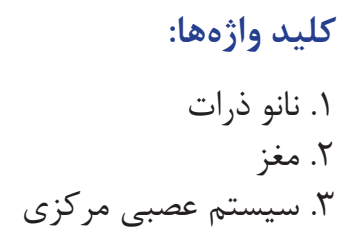

" نويسنده مسئول: فريبا كريم زاده، خديجه اشترى آدرس الكترونيكى: Fariba_karimzade@yahoo.com,ashtaribeh@gmail.com 


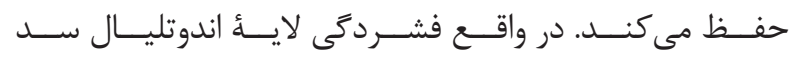

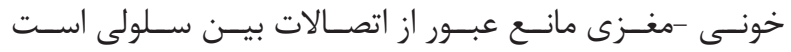

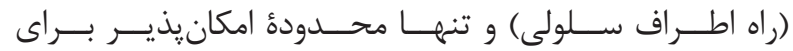

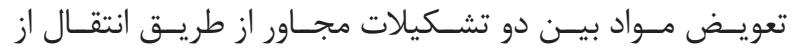

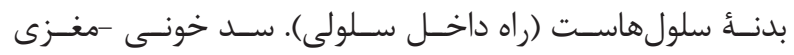

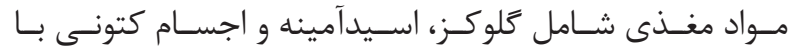

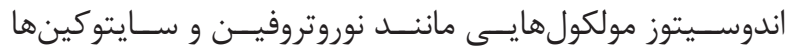

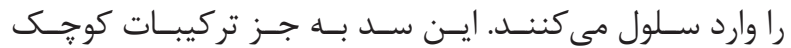

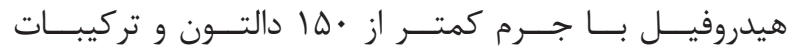

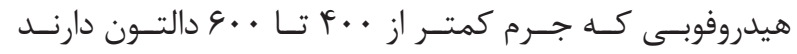

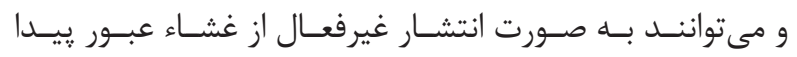

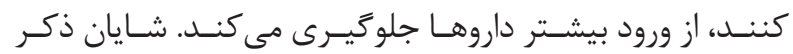

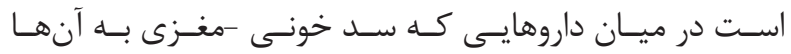

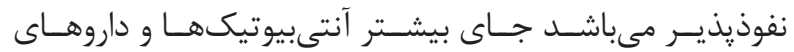

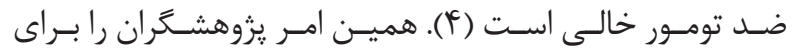

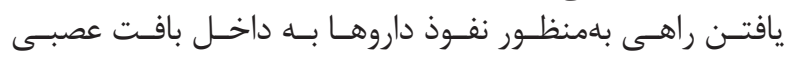

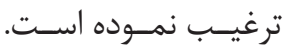

نانو تكنولوزى بهمنظور دارو رسانى به مغز

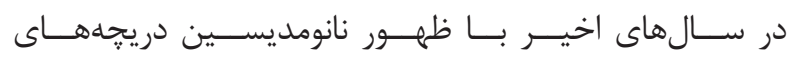

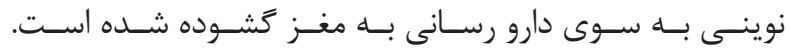

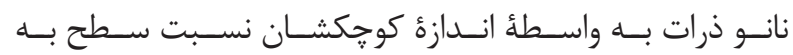

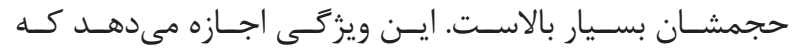

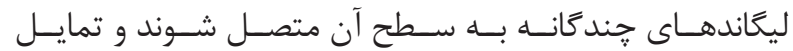

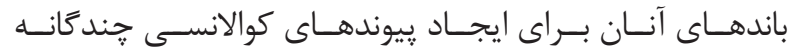

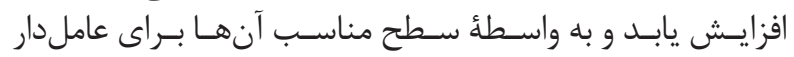

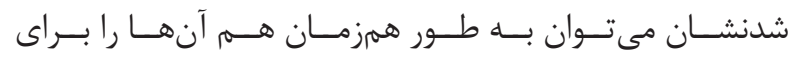

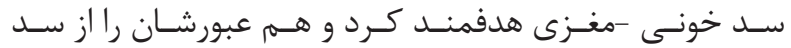

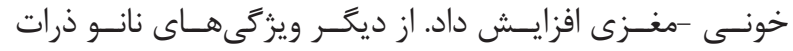

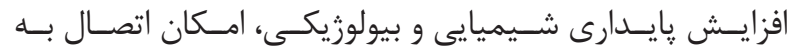

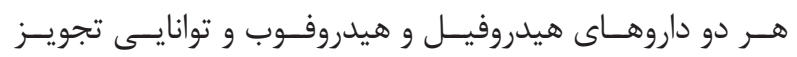

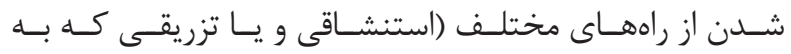

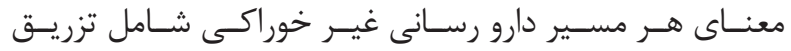

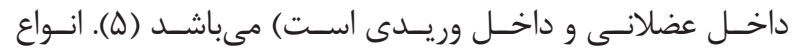

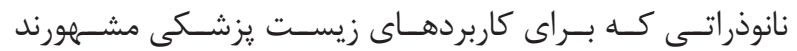

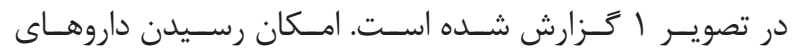

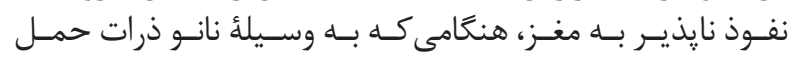

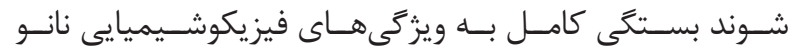

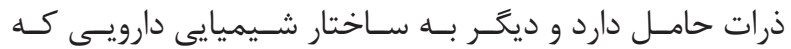

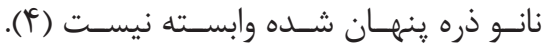

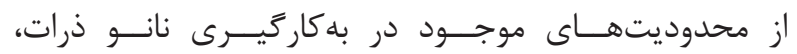

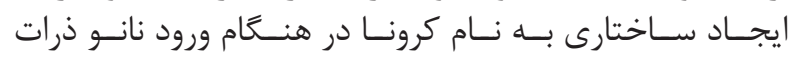

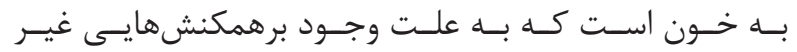

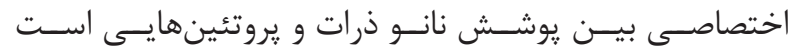

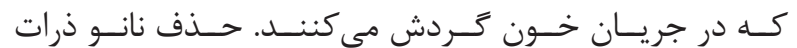

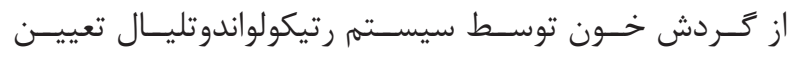

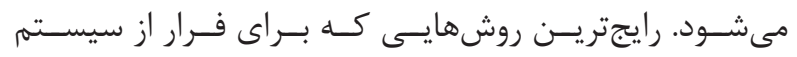

${ }^{1}$ Blood brain barrier

${ }^{2}$ Trojan horse
مقدمه

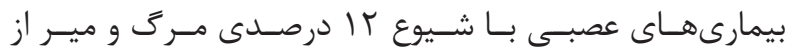

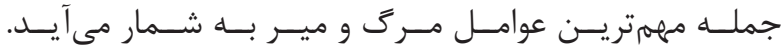

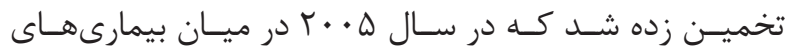

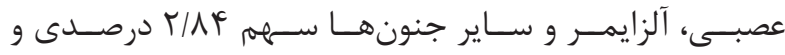

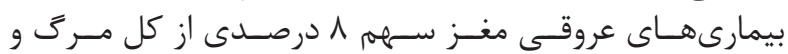

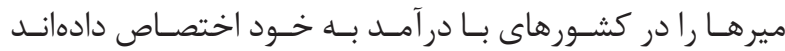

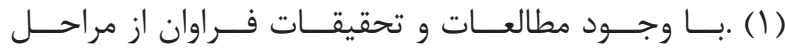

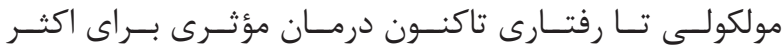

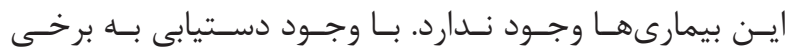

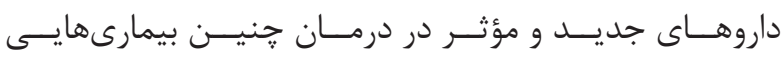

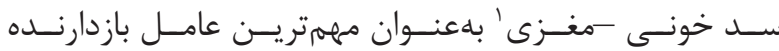

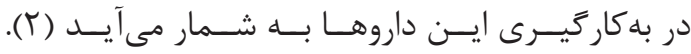

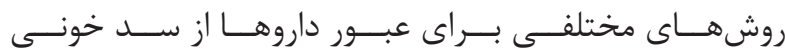

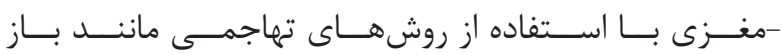

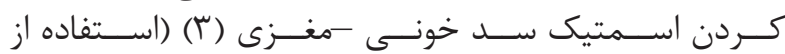

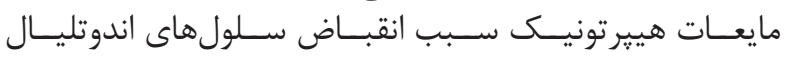

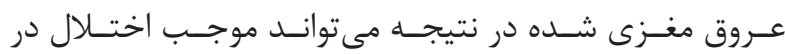

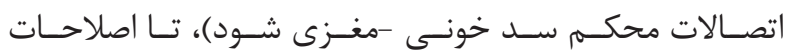

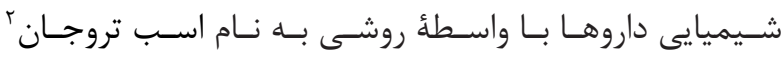

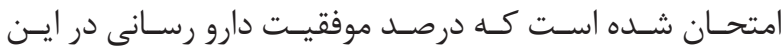

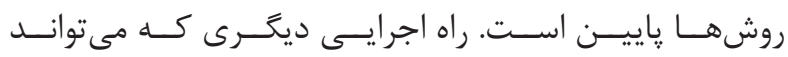

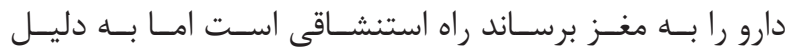

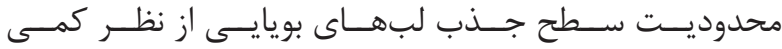

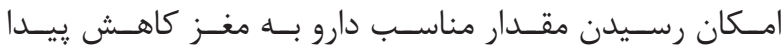

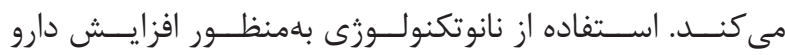

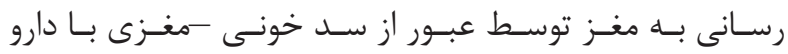

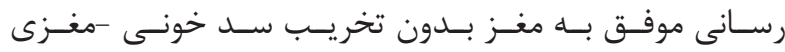

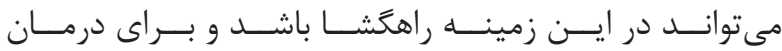

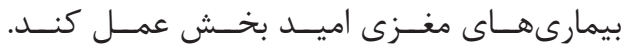

\section{فيزيولوزى سد خونى -مغزى}

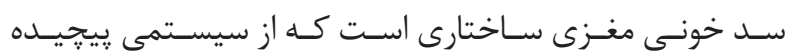

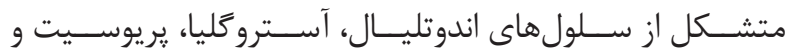

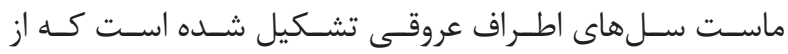

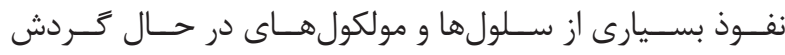

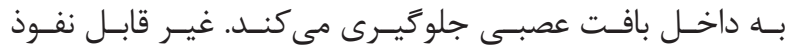

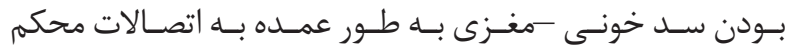

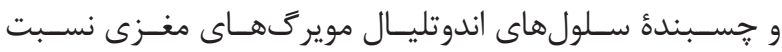

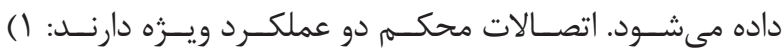

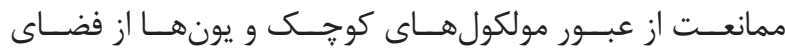

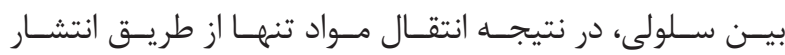

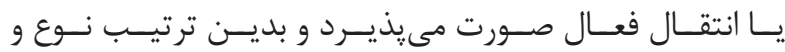

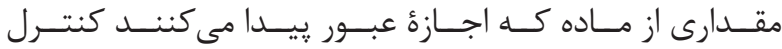

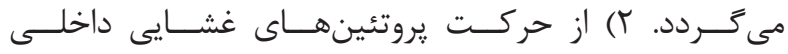

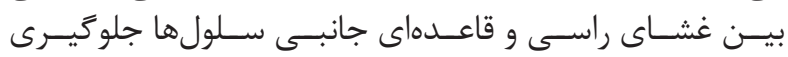

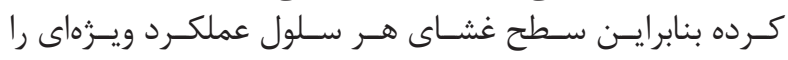


هسـتند كــه در ايــن رابطــهـ مطالعـهـ شــداند.

r - نانو ذرات ليبيدى

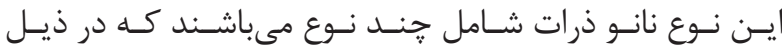

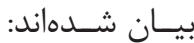

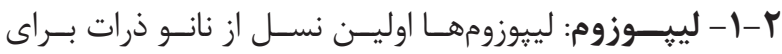

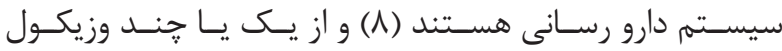

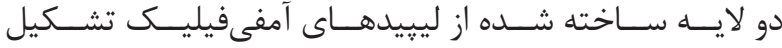

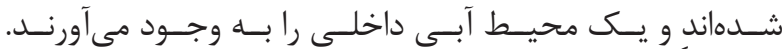

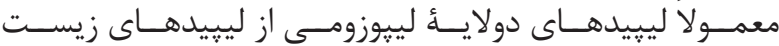

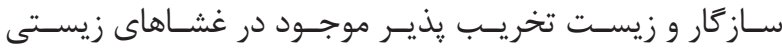

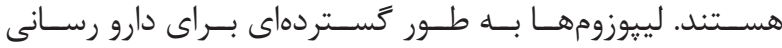

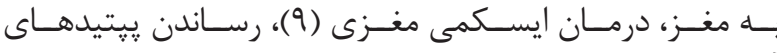

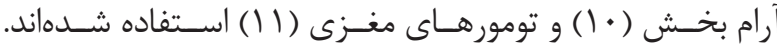

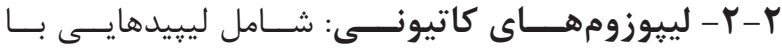

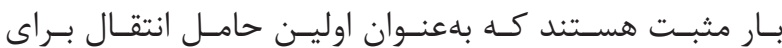

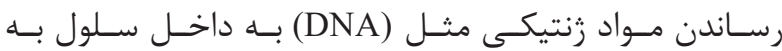

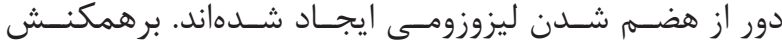

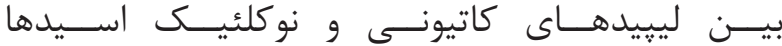

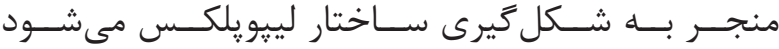

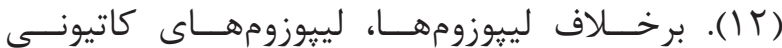

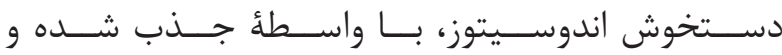

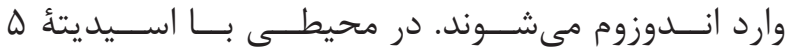

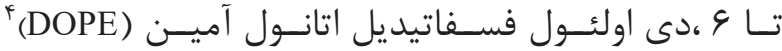

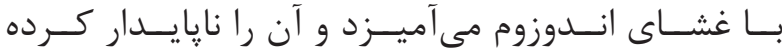

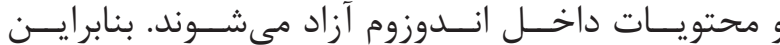

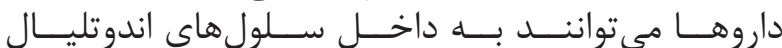

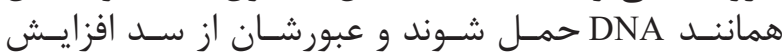

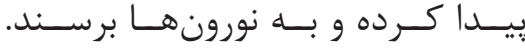

r-r- نانو ذرات ليييدى جامد

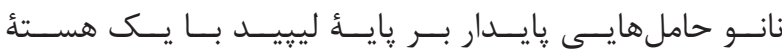

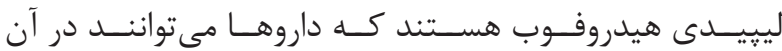

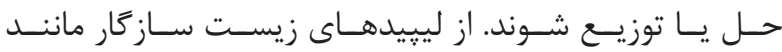

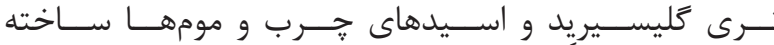

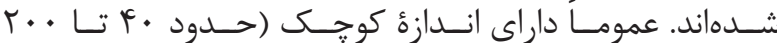

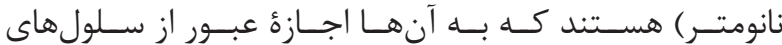

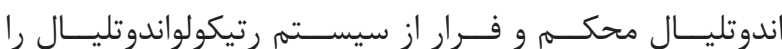

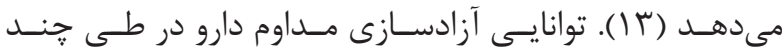

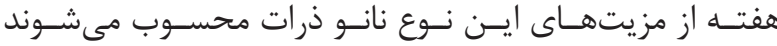

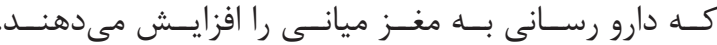

r- نانو ذرات با يايةٌ يليمرى

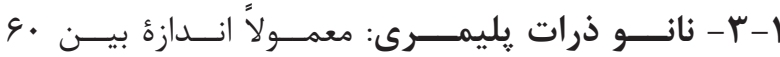

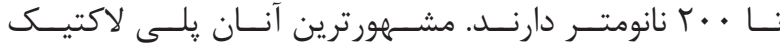

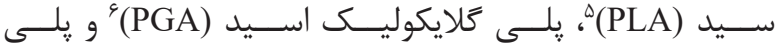

${ }^{3}$ Polyethylene glycol

${ }^{4}$ Dioleoyl-phosphatidylethanolamine

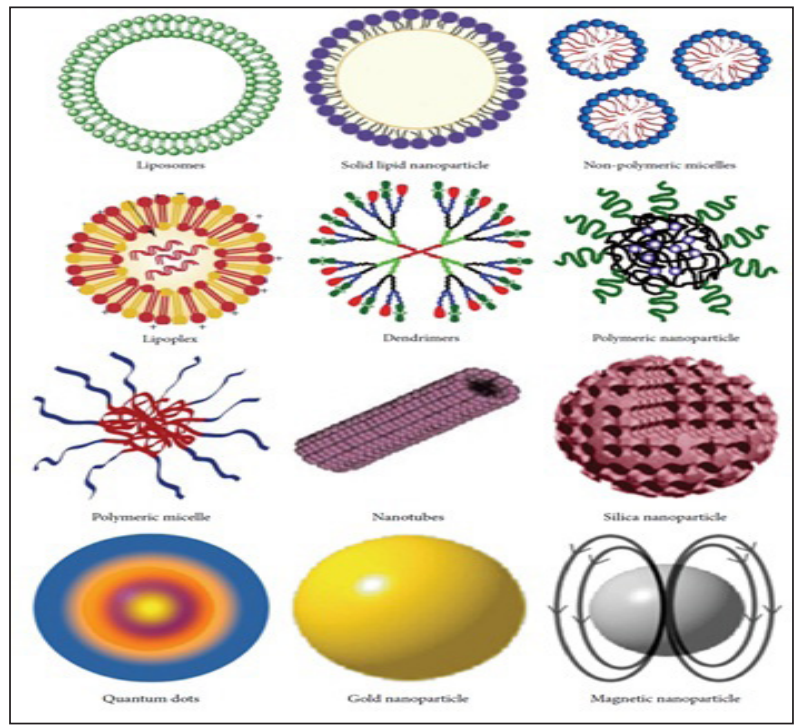

تصوير ا- نمايش كرافيكى رايجترين نانو ذرات كاربردى در زيست يزشكى (\$).

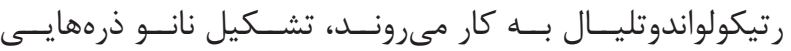

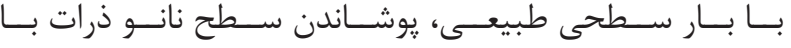

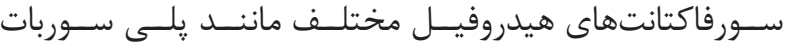

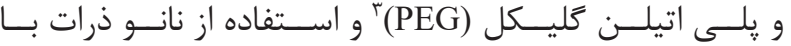

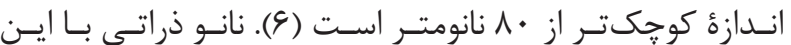

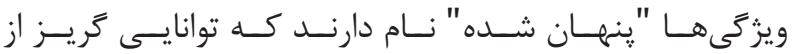

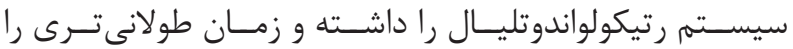

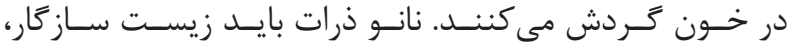

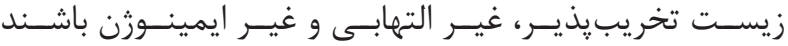

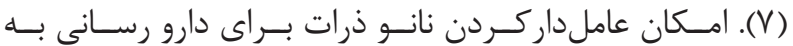

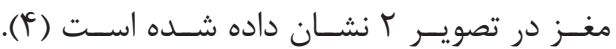

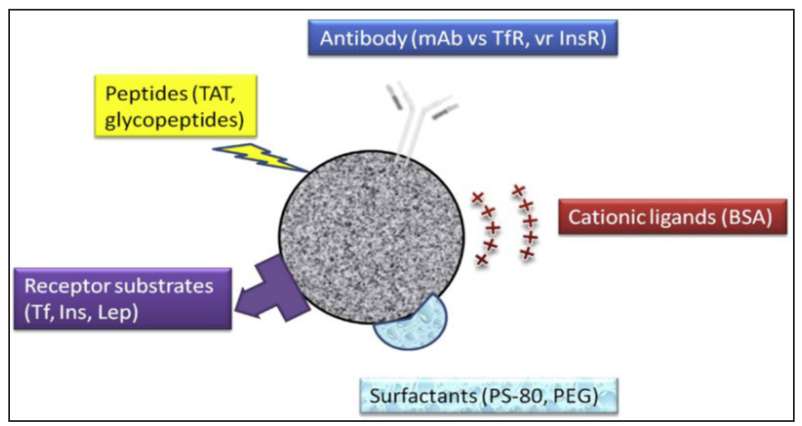

تصوير r- קند عملكردى كردن نانو ذره، نمايش اصلاح سطح نانو ذره با داروها (1). انواع نانو ذرات براى دارو رسانى به مغز

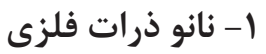

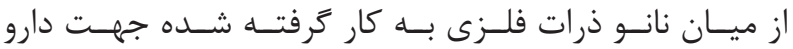

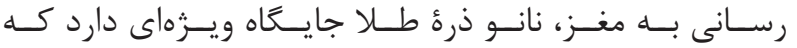

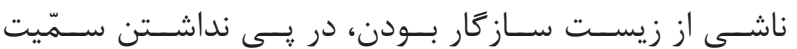

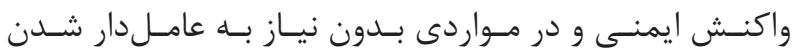

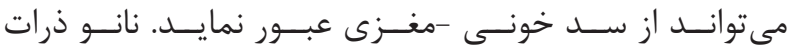

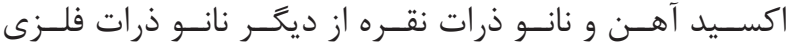

${ }^{5}$ Poly lactic acid

${ }^{6}$ Poly glycolic acid 
محيـط آبـى تجمـع مى كنـــد و منجــر بــهـ توليــد سـاختارهاى

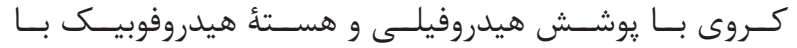

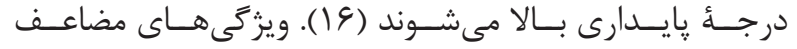

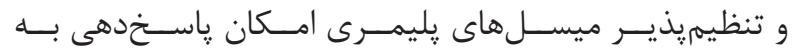

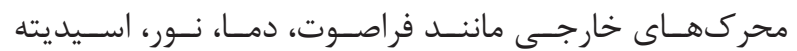

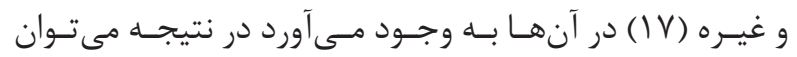

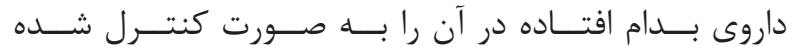

$$
\text { رهاسـازى كـرد. }
$$

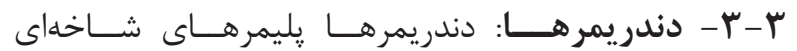

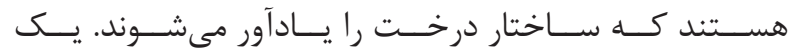

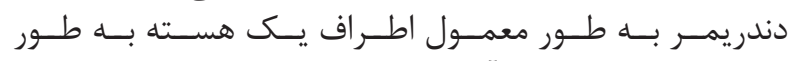

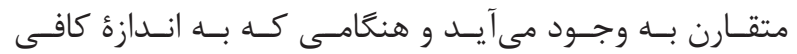

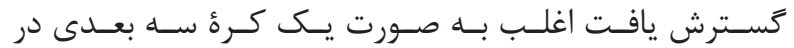

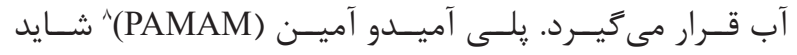

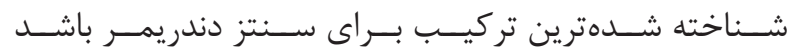

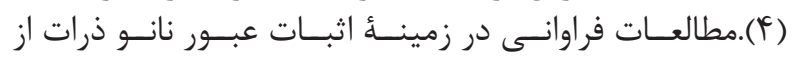

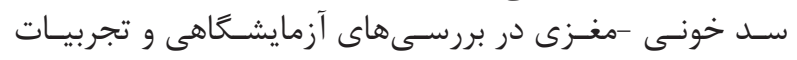

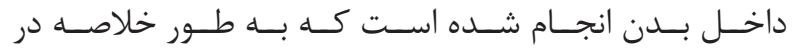

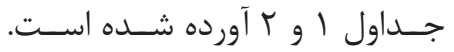

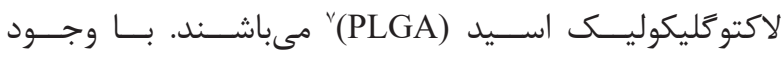

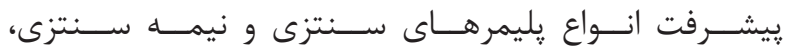

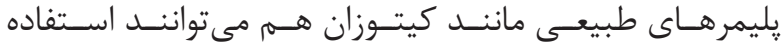

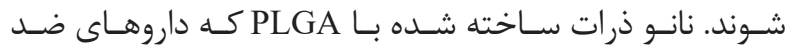

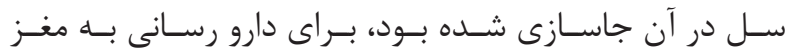

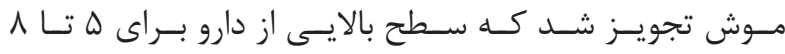

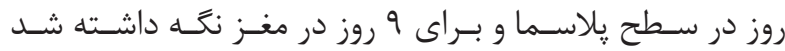

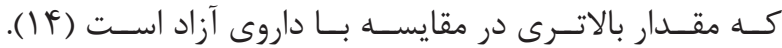

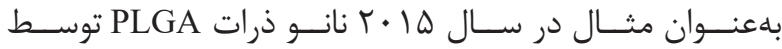

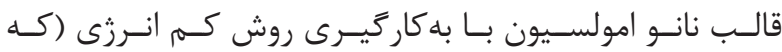

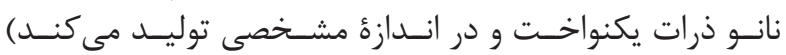

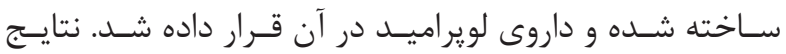

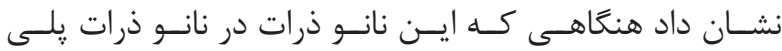

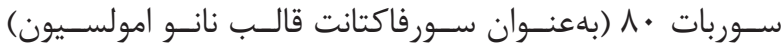

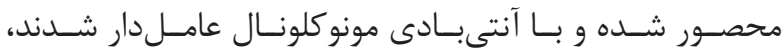

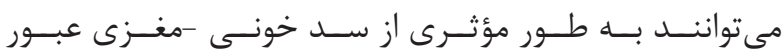

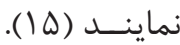

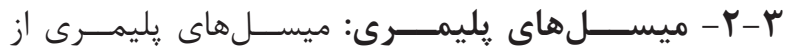

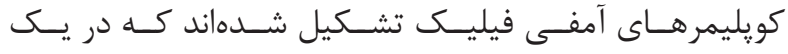

جدول ا- نانو ذرات بررسى شده در محيط آزمايشًاهى براى عبور از BBB (1).

\begin{tabular}{|c|c|c|c|c|c|c|}
\hline سيستم دارو رساتى & بليمر اتركيبات & |داروى لود شدها & ليكاتد & اهداث & نوع آزمايش & منابع \\
\hline ناتو ذرات ليجيـيدى & ليبيد+" & I & I & Factorial design & بقاى سلولى & (19) \\
\hline ناتو ذرات ليبيدى & ليبيد+سورفاكتانت & I & I & Factorial design & سمَيتَ & $\left(r \cdot, T_{1}\right)$ \\
\hline نانو ذرات ليسِيدى جامد & ليجيد+ & كلبنون" & I & اثر آنتىاكسيدانى & (آسيتروسيتهماى اوليه) & (Tr) \\
\hline نانو ذرات ليبيدى جامد & ليجيد+ & كلبنون & I & +نفوذيذِيرى آنتى اكسيدانى & 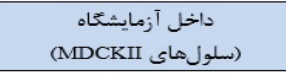 & $(T r \cdot T F)$ \\
\hline نائو ذرات ليِيديدى جامد & ليبيد+ & فروليك اسيد & I & اثت آنتىاكسيدانى & 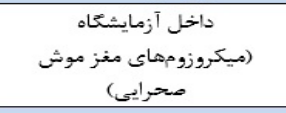 & $(r \Delta)$ \\
\hline نانو ساخو ذرات ليِيبيدى جامل جامد & ليجيد" & فروليك اسيد & I & اثر آيويتيك & داخل آزمايثكاه (كّليوبلانستوما) & (TG. TV) \\
\hline نانو ذرات ليِييدى جامد & لييبد & ياكلى تاكسل ' & I & 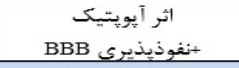 & $\begin{array}{c}\text { داخل آزمايشتخاه } \\
\text { BBB (كليوبلاستوما) }\end{array}$ & $(\mathrm{YA})$ \\
\hline نائو ذرات ليتيدي جامد & ليجيد & دوكسروبيسين & I & ضنف اثتر آيويتيك & 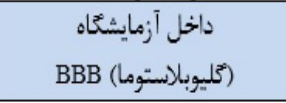 & (Yq) \\
\hline ن ت نانو ذرات & PLGA & I & 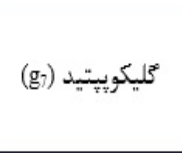 & فرايند أندونيتوز & كشت آسترونسيتهاى اوليه و نوريشّاه & $(r \cdot-r Y)$ \\
\hline 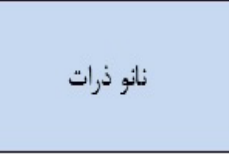 & PLGA & I & "كليكويتيتيد & سرنونشت داخل و بين & كشت آستروسيتهاى اوليه آزمايشّاه & (Tr) \\
\hline 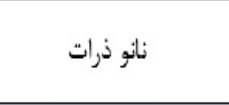 & PLGA & ميوزايمَ" & "تليكويتيتيد & اصلاح كمبود متابوليسم & بيمارى بمدب اوليةٌ فيبروبلاست آزمايشّاه & $\left(r+F^{*}\right.$ \\
\hline ليبززومها & ليبيد & 1 & آبوليبوبروتئين E & برداشت سلولى اندوتليال & داخل آزمايشُّاه (BBB) & $(T \Delta)$ \\
\hline ليتوزومها & ليبيد & I & 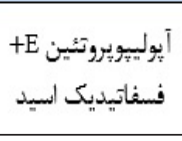 & 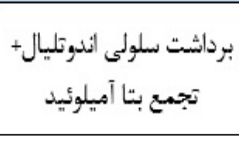 & 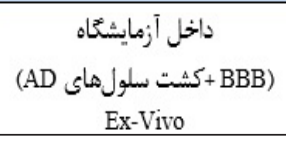 & $(r \xi-r \lambda)$ \\
\hline
\end{tabular}

${ }^{7}$ Poly lactic-co-glycolic acid

${ }^{10}$ Paclitaxel

${ }^{8}$ Polyamidoamine

${ }^{11}$ Doxorubicin

${ }^{9}$ Klebenone

${ }^{12}$ Myozyme 
جدول r- بررسى توزيع زيستى نانو ذرات در شرايط داخل بدن بهمنظور اثبات عبور از سد خونى -مغزى (IF).

\begin{tabular}{|c|c|c|c|c|c|c|}
\hline سيستم دارو رساتى & يليمر /تركيبات & نشارئ لودارى شدها & ل ليكاند & اهداف & ثوع آزمايش & منابع \\
\hline نانو ذرات لييبيدى جامد & ليجيبد & نانو ذرات نشانهكذارى & Tween 80 & ذورات ليجيدي مغزى جامد & 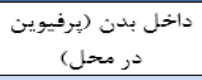 & $(r q-f T)$ \\
\hline ن ن انو ذرات & HSA & , & $\begin{array}{l}\text { آيولييويروتئين } \\
\text { E }\end{array}$ & توزيع مغزى نانو & 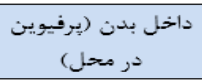 & (fF) \\
\hline ن ن انو ذرات & PHDCA & نانو ذرات نشانه كذارى & PEG & توزيع زيستى نانو & (سيستميكن) & $(\& \Delta)$ \\
\hline ن انو ذرات & PBCA & نانو ذرات نشانه كذارى + & PS-80 & ذورزيع زيستى نانو & (سيستل بدنى) & (*8) \\
\hline ن انو ذرات & PBCA & لدالاركين "H & PS- 80 & غلظت مغزى دارو & (سيستميكى) داخل بدن & $(\& \vee)$ \\
\hline ن انو ذرات & كيتوزان & 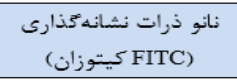 & كلروتوكسينين' & ذورزيع زيستى نانو & (سيسلميكى) & $(\mp \wedge)$ \\
\hline نانو ذرات & كيتوزان+PEG+آكسيد & $\begin{array}{c}\text { نانو ذرات نشاندكّذارى } \\
\text { (Cy5.5) }\end{array}$ & $\begin{array}{c}\text { FAb vs AD } \\
\text { ș }\end{array}$ & توزيعندي زيستى + AD & (سيستميكى) & $(\neq q)$ \\
\hline ن انو ذرات & كيتوزان+PEG & 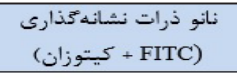 & $\mathrm{OX}-26 \mathrm{mAb}$ & توزيع مغزى نانو & (سيستل بدني) & $(\Delta \cdot)$ \\
\hline ن انو ذرات & PLA & نانو ذرات نشانه كذارى $\begin{array}{c}\text { (FITC) } \\
\text { (FIC) }\end{array}$ & PS-80 & توزيع مغزى نانو & (سيستل بديك) & (ه) \\
\hline ن انو ذرات & PBCA & دوكسروبيسـين & PS-80 & توزيع مغزى دارو & (سيستميكى) & $(\Delta r)$ \\
\hline ن انانو ذرات & PBCA & 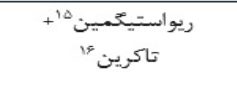 & PS-80 & توزيع مغزى دارو & (سيستميكى) & $(\Delta r \cdot \Delta F)$ \\
\hline ل ل ل ل لييوزومها & ليجبيد + PEG & BSH & $\begin{array}{l}\text { mAb vs / } \\
\text { glioma }\end{array}$ & توزيع مغزي دارو + & 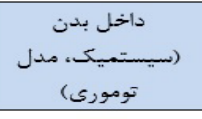 & $(\Delta \Delta)$ \\
\hline ل ل ل ل لييوزومها & ليبيد + PEG & Daunomicyn & $\mathrm{OX} 26 \mathrm{mAb}$ & توزيع مغزى دارو & (سيستميك) بدن) & $(\Delta s-\Delta \Lambda)$ \\
\hline نانو ذرات ليبيـدى جامد & ليجيسيد & 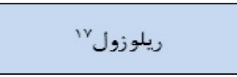 & 1 & توزيع داروى مغز & (سيستميك) بدن) & $(\Delta Q)$ \\
\hline
\end{tabular}

همكنـش الكتروسـتاتيك برقــرار كنـــــ. داشـتن بارهــاى

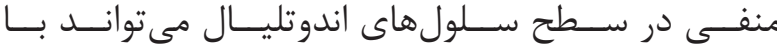

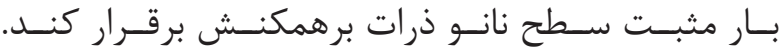

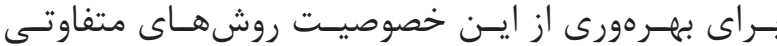

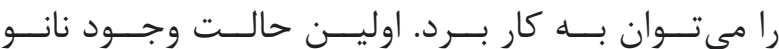

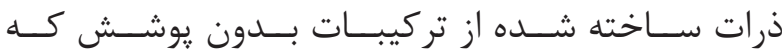

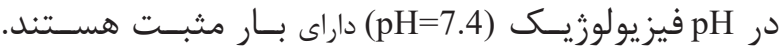

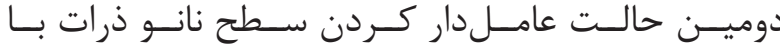

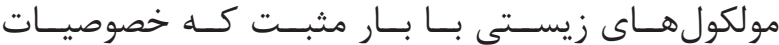

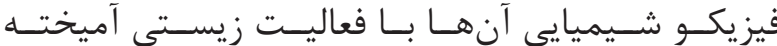

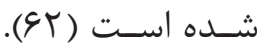

\section{r- عبور از داخل سلول با واسطئ كيرنده}

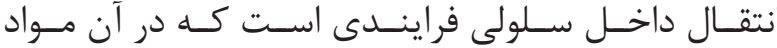

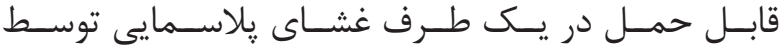

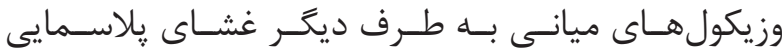

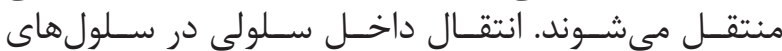

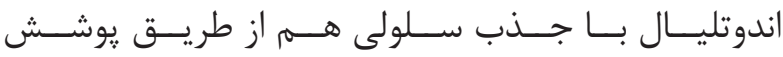

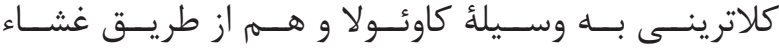

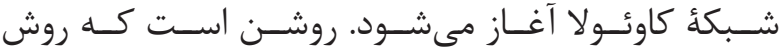

${ }^{13}$ Dalargin

${ }^{14}$ Clorotoxin

${ }^{15}$ Rivastigmine

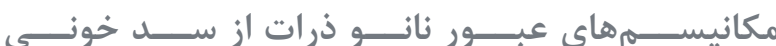

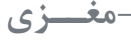

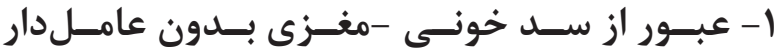
كــر دن

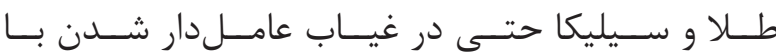

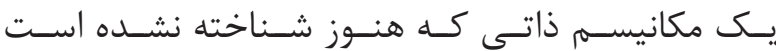

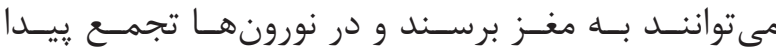

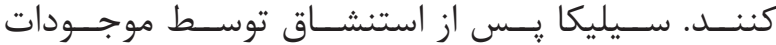

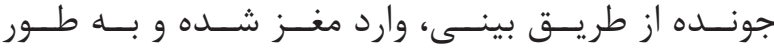

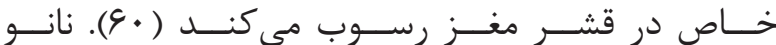

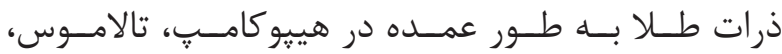

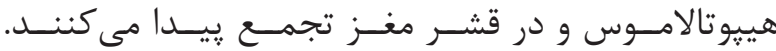

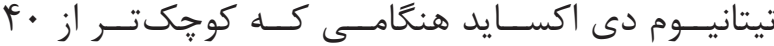

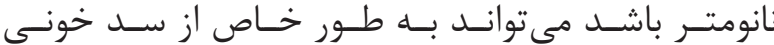

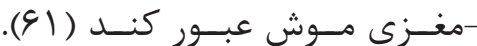

r- عبور از داخل سلول با واسطهُ جذب

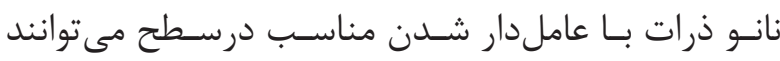

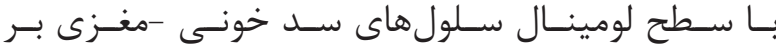

${ }^{16}$ Tacrine

${ }^{17}$ Riluzole 


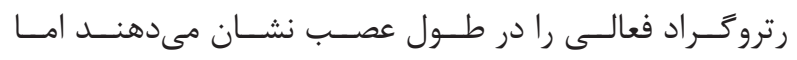

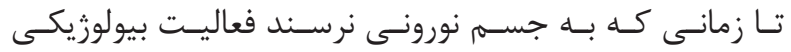

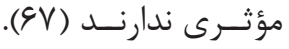

\section{ه- از كار افتادكى سد خونى -مغزى لهارلى}

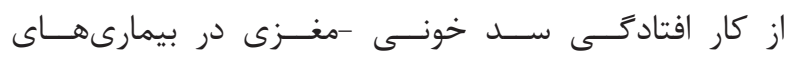

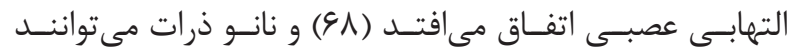

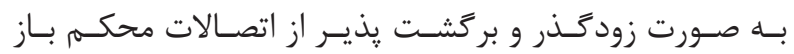

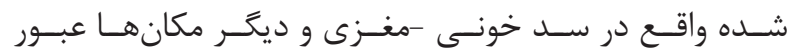

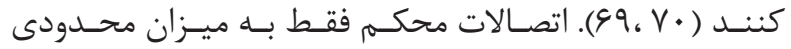

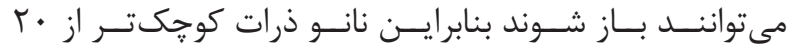

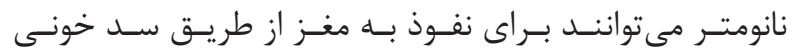

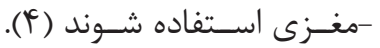

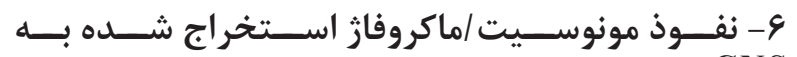

CNS

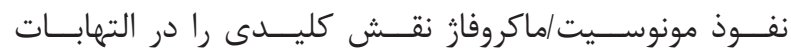

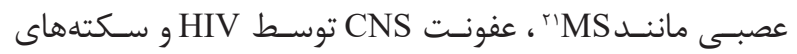

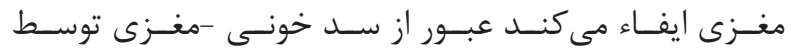

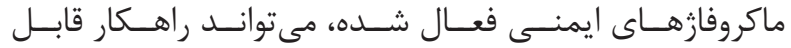

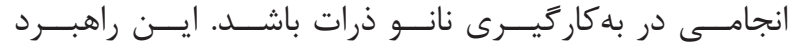

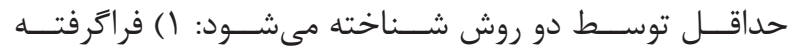

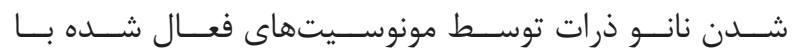

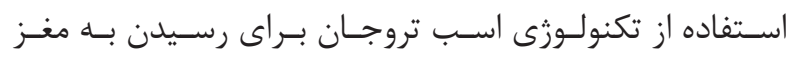

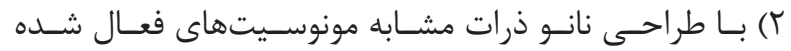

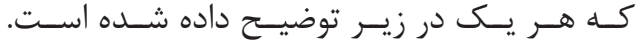

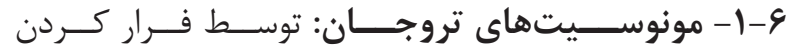

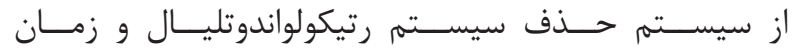

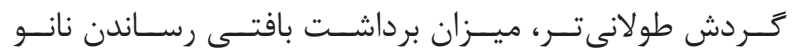

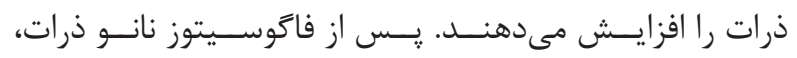

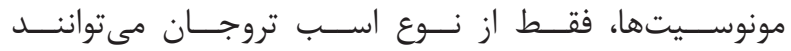

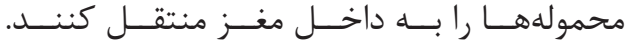

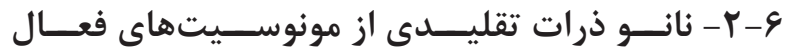

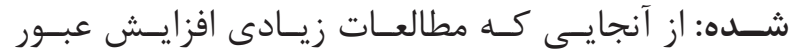

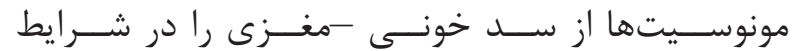

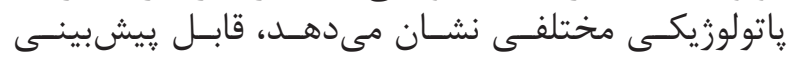

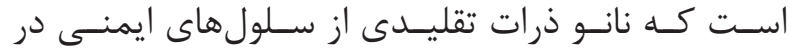

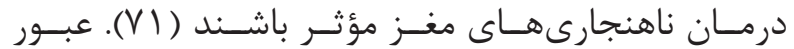

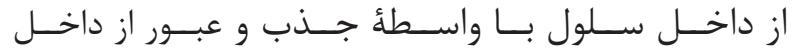

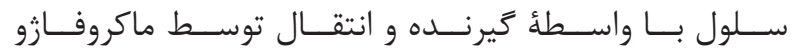

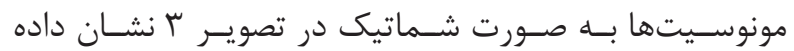

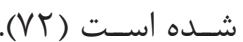

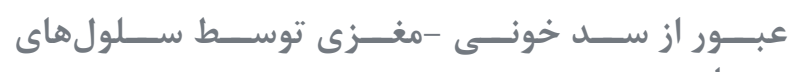

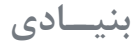

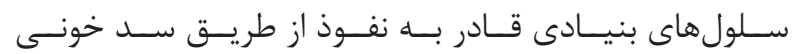

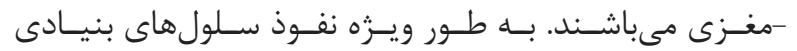

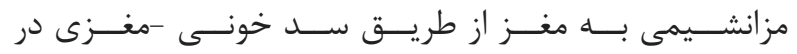

${ }^{18}$ Mono sialo tetrahexosyl ganglioside

${ }^{19}$ Plaques

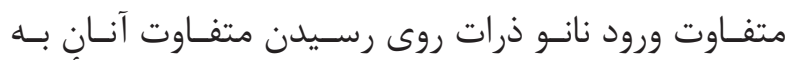

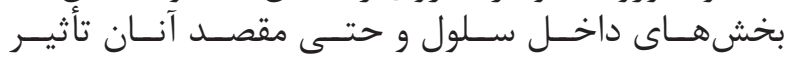

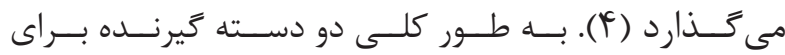

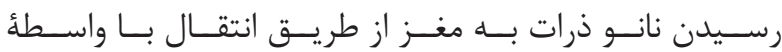

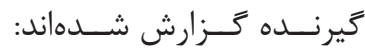

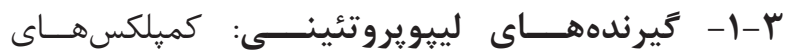

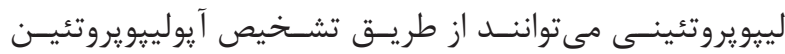

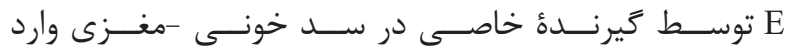

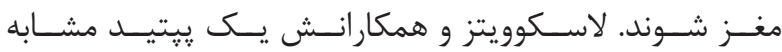

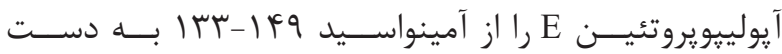

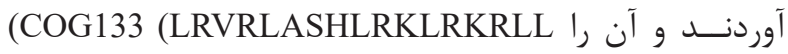

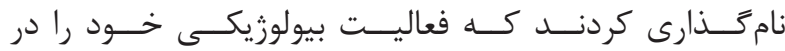

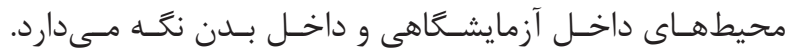

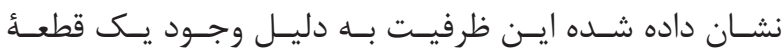

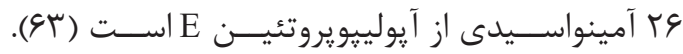

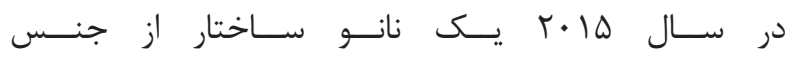

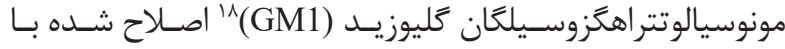

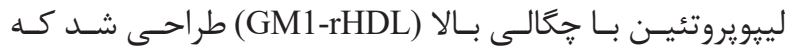

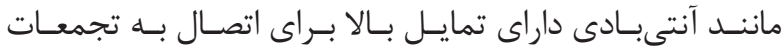

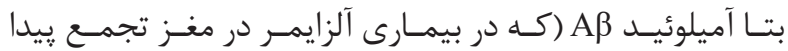

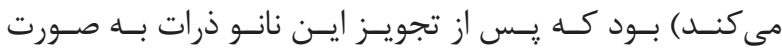

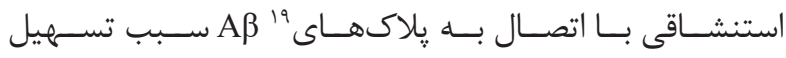

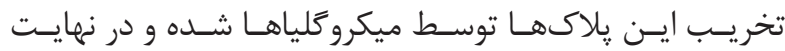

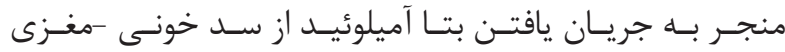

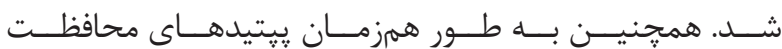

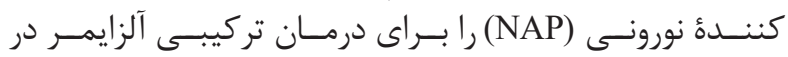

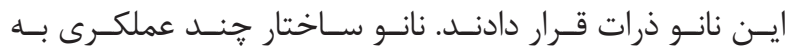

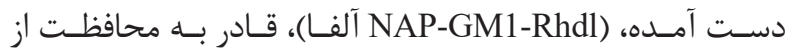

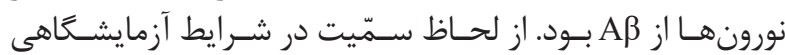

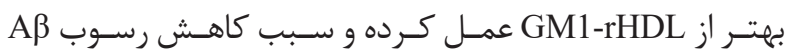

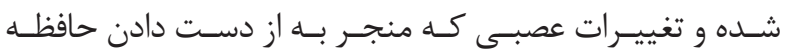
مىشـود را بهبــود بخشـيد (94).

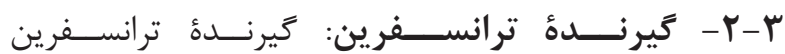

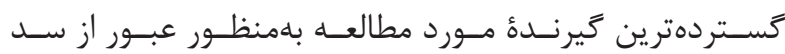

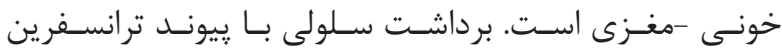

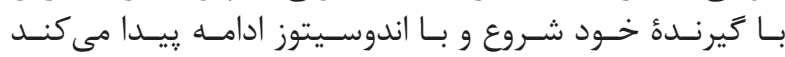

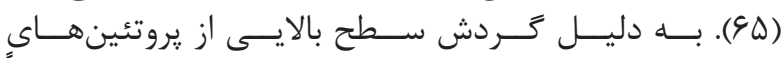

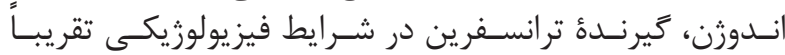

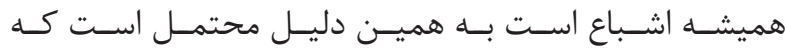

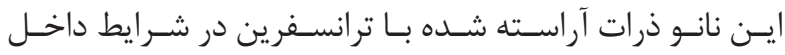

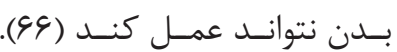

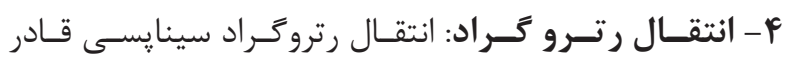

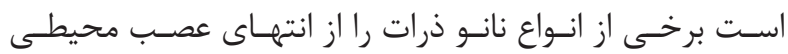

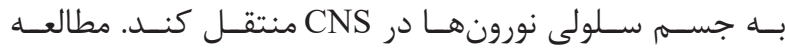

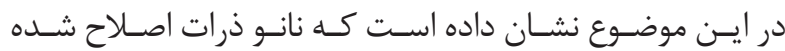

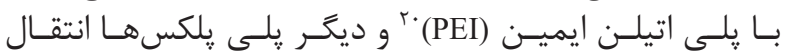

${ }^{20}$ Poly ethylene imine

${ }^{21}$ Multiple sclerosis 


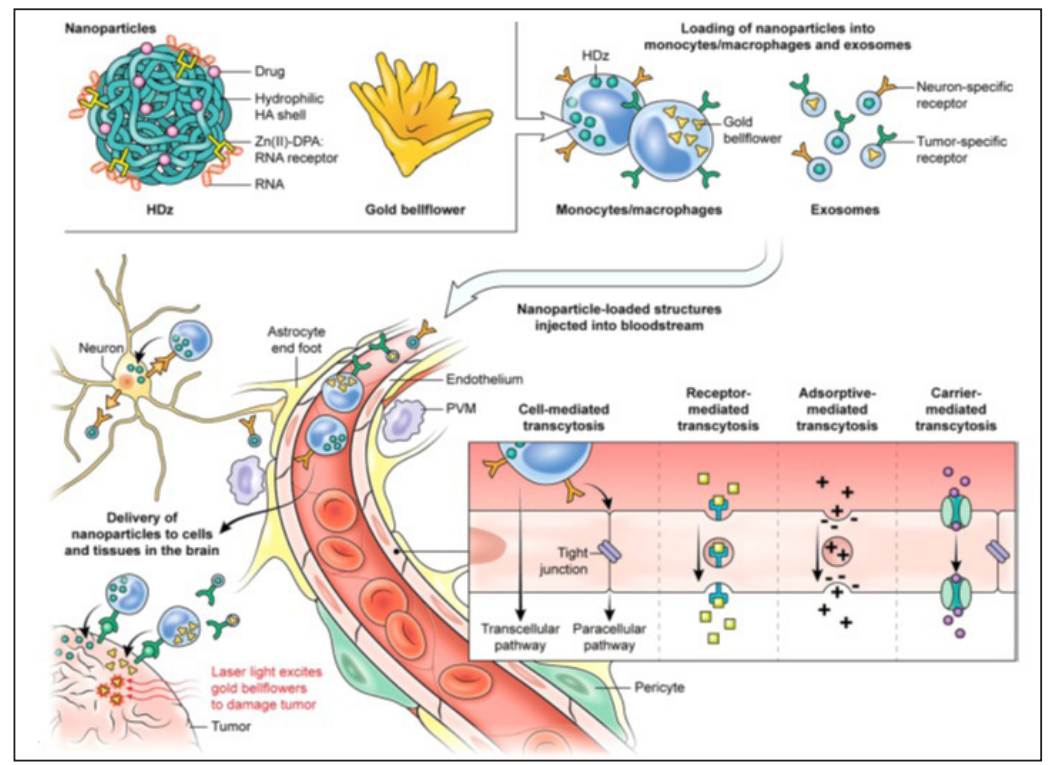

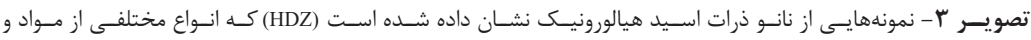

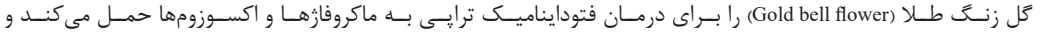

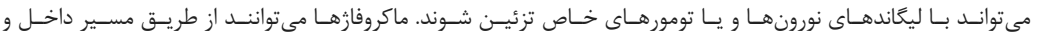

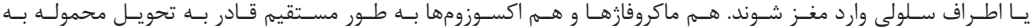

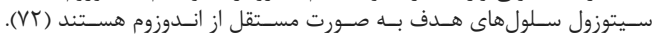

آلبوميـن از خــردش خــون وارد يارانشـيمم مغـزى مىشـود (†). F

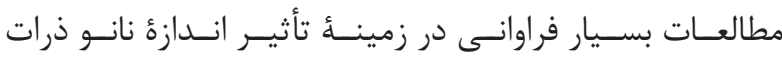

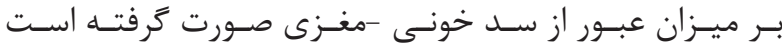

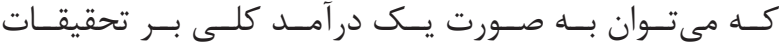

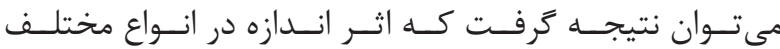

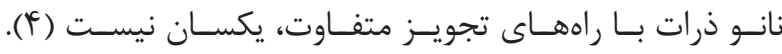

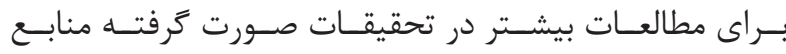

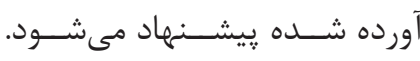

$$
\text { سمّيت عصبى نانو ذرات }
$$

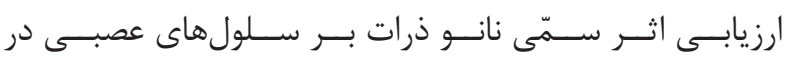

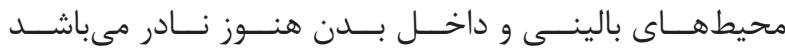

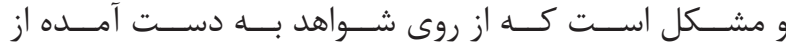

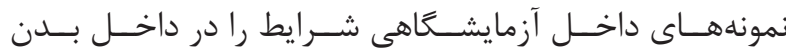

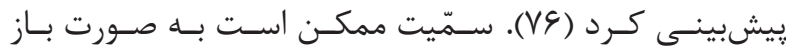

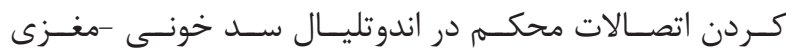

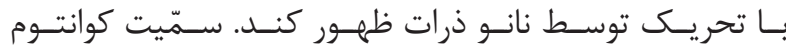

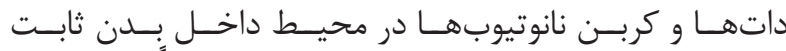

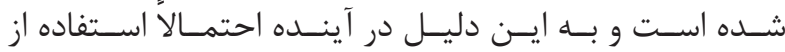

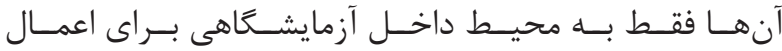

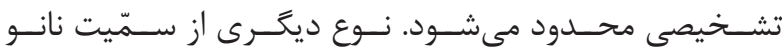

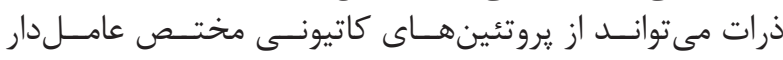

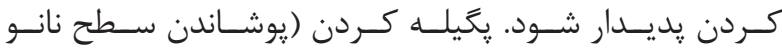

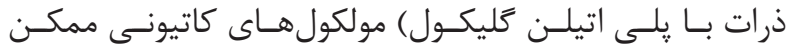

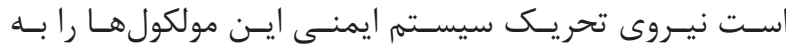

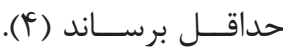

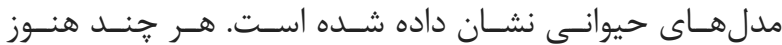

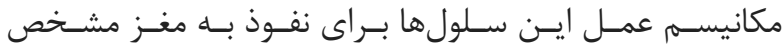
. (VT, VY)

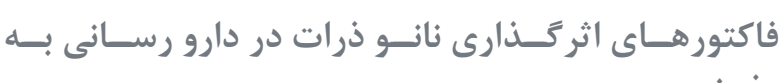
مغنـز

1- انتشار نانو ذرات به داخل یارانشيم مغزى

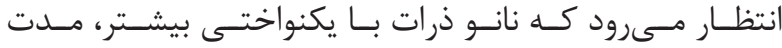

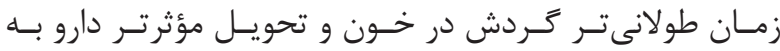

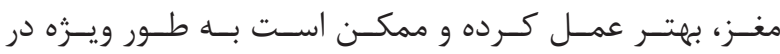

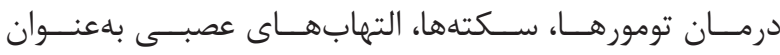

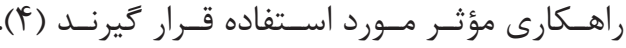
r- تأثير يروتئين كرونا

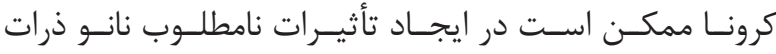

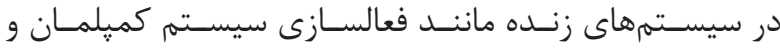

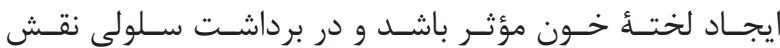
ضـرورى ايفـاء كنــد (VQ)

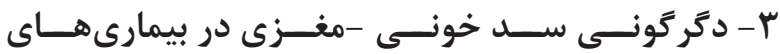
عصبــى

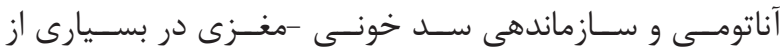

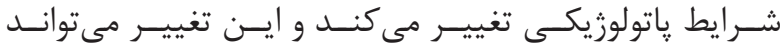

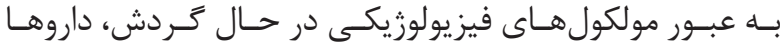

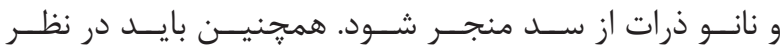

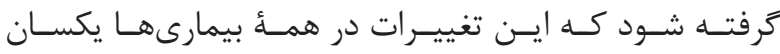

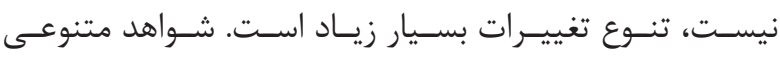

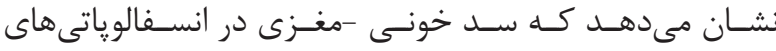

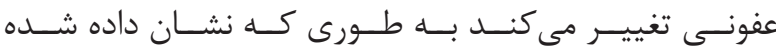




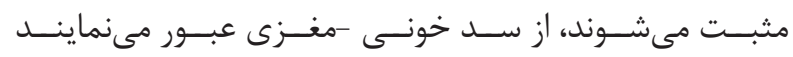

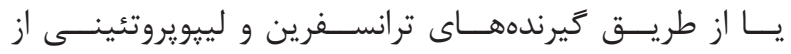

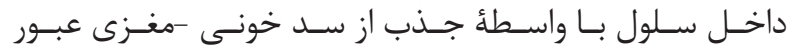

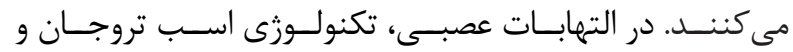

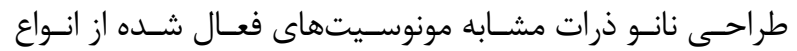

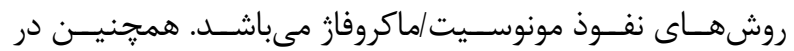

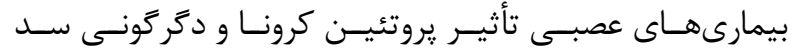

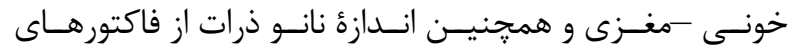

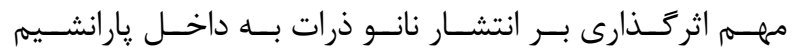

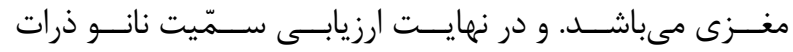

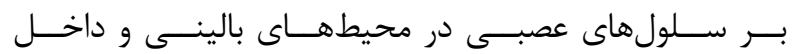

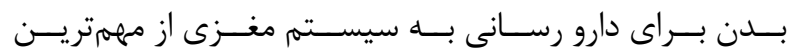

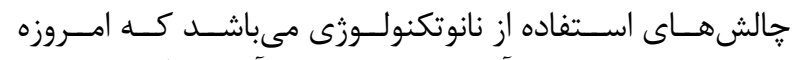

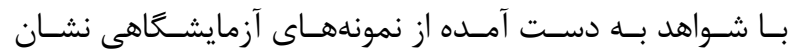

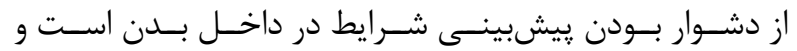

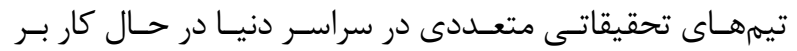

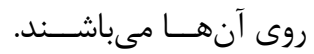

1. Honjo K, Black SE, Verhoeff NP. Alzheimer's disease, cerebrovascular disease, and the $\beta$-amyloid cascade. Can J Neurol Sci. 2012; 39(06): 712-28.

2. Kanwar JR, Sriramoju B, Kanwar RK. Neurological disorders and therapeutics targeted to surmount the blood-brain barrier. Int J Nanomedicine. 2012; 7: 3259-78.

3. Bellavance M-A, Blanchette M, Fortin D. Recent advances in blood-brain barrier disruption as a CNS delivery strategy. AAPS J. 2008; 10(1): 166-77.

4. Masserini M. Nanoparticles for brain drug delivery. ISRN Biochem. 2013; 18. doi: 10.1155/2013/238428.

5. Petkar KC, Chavhan SS, Agatonovik-Kustrin S, Sawant K. Nanostructured materials in drug and gene delivery: a review of the state of the art. Crit Rev Ther Drug Carrier Syst. 2011; 28(2): 101-64.

6. Provenzale J, Silva G. Uses of nanoparticles for central nervous system imaging and therapy. AJNR Am J Neuroradiol. 2009; 30(7): 1293-301.

7. Gabathuler R. Approaches to transport therapeutic drugs across the blood-brain barrier to treat brain diseases. Neurobiol Dis. 2010; 37(1): 48-57.

8. Budai M, Szogyi M. [Liposomes as drug carrier systems. Preparation, classification and therapeutic advantages of liposomes]. Acta Pharm Hung. 2000; 71(1): 114-8.

9. Fukuta T, Ishii T, Asai T, Sato A, Kikuchi T, Shimizu K, et al. Treatment of stroke with liposomal neuroprotective
نتيجه گيرى

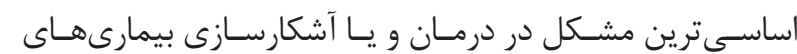

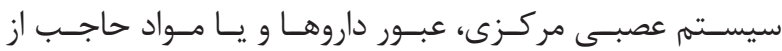

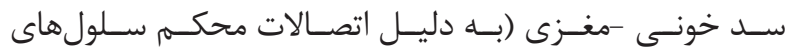

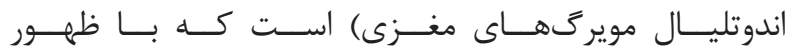

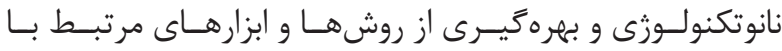

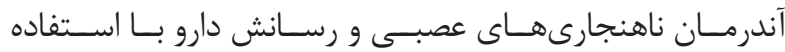

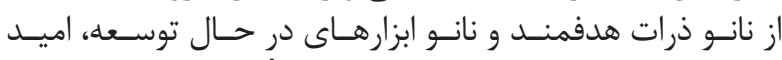

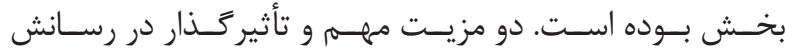

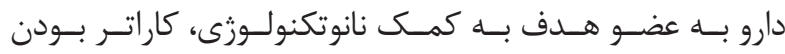

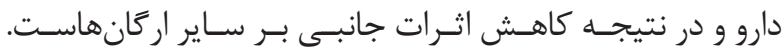

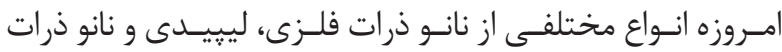

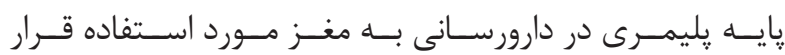

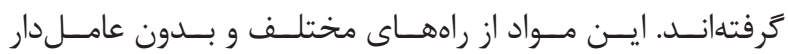

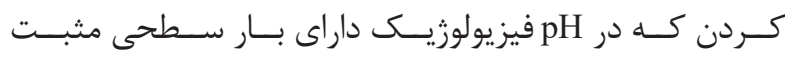

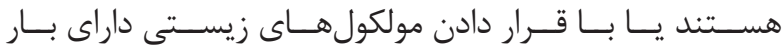

منابع

agents under cerebral ischemia conditions. Eur J Pharm Biopharm. 2015; 97(Pt A): 1-7.

10. Lindqvist A, Rip J, Gaillard PJ, Björkman S, Hammarlund-Udenaes M. Enhanced brain delivery of the opioid peptide DAMGO in glutathione pegylated liposomes: a microdialysis study. Mol Pharm. 2012; 10(5): 1533-41.

11. Orthmann A, Zeisig R, Süss R, Lorenz D, Lemm M, Fichtner I. Treatment of experimental brain metastasis with MTO-liposomes: impact of fluidity and LRPtargeting on the therapeutic result. Pharm Res. 2012; 29(7): 1949-59.

12. Artzner F, Zantl R, Rädler J. Lipid-DNA and lipidpolyelectrolyte mesophases: structure and exchange kinetics. Cell Mol Biol (Noisy-le-grand). 2000; 46(5): 967-78.

13. Pardeshi C, Rajput P, Belgamwar V, Tekade A, Patil G, Chaudhary K, et al. Solid lipid based nanocarriers: an overview/Nanonosači na bazi čvrstih lipida: Pregled. Acta Pharm. 2012; 62(4): 433-72.

14. Pandey R, Khuller G. Oral nanoparticle-based antituberculosis drug delivery to the brain in an experimental model. J Antimicrob Chemother. 2006; 57(6): 1146-52.

15. Fornaguera C, Dols-Perez A, Caldero G, GarciaCelma M, Camarasa J, Solans C. PLGA nanoparticles prepared by nano-emulsion templating using low-energy methods as efficient nanocarriers for drug delivery across the blood-brain barrier. J Control Release. 2015; 211: 134-43. 
16. Mishra B, Patel BB, Tiwari S. Colloidal nanocarriers: a review on formulation technology, types and applications toward targeted drug delivery. Nanomedicine. 2010; 6(1): 9-24.

17. Kabanov AV, Batrakova EV, Melik-Nubarov NS, Fedoseev NA, Dorodnich TY, Alakhov VY, et al. A new class of drug carriers: micelles of poly (oxyethylene)-poly (oxypropylene) block copolymers as microcontainers for drug targeting from blood in brain. J Control Release. 1992; 22(2): 141-57.

18. Tosi G, Musumeci T, Ruozi B, Carbone C, Belletti D, Pignatello R, et al. The "fate" of polymeric and lipid nanoparticles for brain delivery and targeting: strategies and mechanism of blood-brain barrier crossing and trafficking into the central nervous system. J Drug Deliv Sci Technol. 2016; 32: 66-76.

19. Carbone C, Tomasello B, Ruozi B, Renis M, Puglisi G. Preparation and optimization of PIT solid lipid nanoparticles via statistical factorial design. Eur J Med Chem. 2012; 49: 110-7.

20. Blasi P, Schoubben A, Traina G, Manfroni G, Barberini L, Alberti PF, et al. Lipid nanoparticles for brain targeting III. long-term stability and in vivo toxicity. IInt J Pharm. 2013; 454(1): 316-23.

21. Blasi P, Giovagnoli S, Schoubben A, Puglia C, Bonina F, Rossi C, et al. Lipid nanoparticles for brain targeting I. formulation optimization. Int J Pharm. 2011; 419(1): 287-95.

22. Montenegro L, Campisi A, Sarpietro MG, Carbone C, Acquaviva R, Raciti G, et al. In vitro evaluation of idebenone-loaded solid lipid nanoparticles for drug delivery to the brain. Drug Dev Ind Pharm. 2011; 37(6): 737-46.

23. Montenegro L, Trapani A, Latrofa A, Puglisi G. In vitro evaluation on a model of blood brain barrier of idebenone-loaded solid lipid nanoparticles. J Nanosci Nanotechnol. 2012; 12(1): 330-7.

24. Denora N, Laquintana V, Lopedota A, Serra M, Dazzi L, Biggio G, et al. Novel L-dopa and dopamine prodrugs containing a 2-phenyl-imidazopyridine moiety. Pharm Res. 2007; 24(7): 1309-24.

25. Trombino S, Cassano R, Ferrarelli T, Barone E, Picci N, Mancuso C. Trans-ferulic acid-based solid lipid nanoparticles and their antioxidant effect in rat brain microsomes. Colloids Surf B Biointerfaces. 2013; 109: 273-9.

26. Carbone C, Campisi A, Musumeci T, Raciti G, Bonfanti R, Puglisi G. FA-loaded lipid drug delivery systems: preparation, characterization and biological studies. Eur J Pharm Sci. 2014; 52: 12-20.

27. Carbone C, Campisi A, Manno D, Serra A, Spatuzza M, Musumeci T, et al. The critical role of didodecyldimethylammonium bromide on physicochemical, technological and biological properties of NLC. Colloids Surf B Biointerfaces. 2014; 121: 1-10.

28. Chirio D, Gallarate M, Peira E, Battaglia L, Muntoni E, Riganti C, et al. Positive-charged solid lipid nanoparticles as paclitaxel drug delivery system in glioblastoma treatment. Eur J Pharm Biopharm. 2014; 88(3): $746-58$

29. Battaglia L, Gallarate M, Peira E, Chirio D, Muntoni E, Biasibetti E, et al. Solid lipid nanoparticles for potential doxorubicin delivery in glioblastoma treatment: Preliminary in vitro studies. J Pharm Sci. 2014; 103(7): 2157-65

30. Grabrucker A, Garner C, Boeckers T, Bondioli L, Ruozi B. Development of novel $\mathrm{Zn} 2+$ loaded nanoparticles designed for cell-type targeted drug release in CNS neurons: in vitro evidences. PLoS One. 2011; 6(3): e17851. doi: 10.1371/journal.pone.0017851.

31. Vilella A, Tosi G, Grabrucker AM, Ruozi B, Belletti $\mathrm{D}$, Vandelli MA, et al. Insight on the fate of CNStargeted nanoparticles. part I: Rab5-dependent cellspecific uptake and distribution. J Control Release. 2014; 174: 195-201.

32. Tosi G, Vilella A, Chhabra R, Schmeisser MJ, Boeckers TM, Ruozi B, et al. Insight on the fate of CNS-targeted nanoparticles. part II: intercellular neuronal cell-to-cell transport. J Control Release. 2014; 177: 96-107.

33. Chhabra R, Grabrucker AM, Veratti P, Belletti D, Boeckers TM, Vandelli MA, et al. Characterization of lysosome-destabilizing DOPE/PLGA nanoparticles designed for cytoplasmic drug release. Int $\mathrm{J}$ Pharm. 2014; 471(1): 349-57.

34. Brunella T, Giovanni T, Barbara B, Diego D, Alessandro M, Eleonora DM, et al. Use of polylactideco-glycolide-nanoparticles for lysosomal delivery of a therapeutic enzyme in glycogenosis type ii fibroblasts. J Nanosci Nanotechnol. 2015; 15(4): 2657-66.

35. Re F, Cambianica I, Zona C, Sesana S, Gregori M, Rigolio R, et al. Functionalization of liposomes with ApoE-derived peptides at different density affects cellular uptake and drug transport across a blood-brain barrier model. Nanomedicine. 2011; 7(5): 551-9.

36. Bana L, Minniti S, Salvati E, Sesana S, Zambelli 


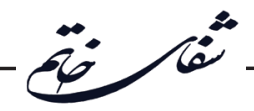

V, Cagnotto A, et al. Liposomes bi-functionalized with phosphatidic acid and an ApoE-derived peptide affect $\mathrm{A} \beta$ aggregation features and cross the blood-brainbarrier: Implications for therapy of Alzheimer disease. Nanomedicine. 2014; 10(7): 1583-90.

37. Salvati E, Re F, Sesana S, Cambianica I, Sancini $\mathrm{G}$, Masserini $\mathrm{M}$, et al. Liposomes functionalized to overcome the blood-brain barrier and to target amyloid- $\beta$ peptide: the chemical design affects the permeability across an in vitro model. Int J Nanomedicine. 2013; 8: 1749-58.

38. Canovi M, Markoutsa E, Lazar AN, Pampalakis G, Clemente $\mathrm{C}$, Re F, et al. The binding affinity of antiA $\beta 1-42$ MAb-decorated nanoliposomes to $A \beta 1-42$ peptides in vitro and to amyloid deposits in post-mortem tissue. Biomaterials. 2011; 32(23): 5489-97.

39. Koziara JM, Lockman PR, Allen DD, Mumper RJ. In situ blood-brain barrier transport of nanoparticles. Pharm Res. 2003; 20(11): 1772-8.

40. Lockman PR, Koziara J, Roder KE, Paulson J, Abbruscato TJ, Mumper RJ, et al. In vivo and in vitro assessment of baseline blood-brain barrier parameters in the presence of novel nanoparticles. Pharm Res. 2003;

20(5): 705-13.

41. Lockman PR, Oyewumi MO, Koziara JM, Roder KE, Mumper RJ, Allen DD. Brain uptake of thiaminecoated nanoparticles. J Control Release. 2003; 93(3): 271-82.

42. Allen D, Oki J, Smith Q. An update in the in situ rat brain perfusion technique: simpler, faster, better. Pharm Res. 1997; 14: 337.

43. Koziara JM, Lockman PR, Allen DD, Mumper RJ. Paclitaxel nanoparticles for the potential treatment of brain tumors. J Control Release. 2004; 99(2): 259-69.

44. Zensi A, Begley D, Pontikis C, Legros C, Mihoreanu L, Wagner S, et al. Albumin nanoparticles targeted with Apo E enter the CNS by transcytosis and are delivered to neurones. J Control Release. 2009; 137(1): 78-86.

45. Calvo P, Gouritin B, Chacun H, Desmaële D, D'Angelo J, Noel J-P, et al. Long-circulating PEGylated polycyanoacrylate nanoparticles as new drug carrier for brain delivery. Pharm Res. 2001; 18(8): 1157-66.

46. Ambruosi A, Gelperina S, Khalansky A, Tanski S, Theisen A, Kreuter J. Influence of surfactants, polymer and doxorubicin loading on the anti-tumour effect of poly (butyl cyanoacrylate) nanoparticles in a rat glioma model. J Microencapsul. 2006; 23(5): 582-92.
47. Schroeder U, Schroeder H, Sabel B. Body distribution of $3 \mathrm{HH}$-labelled dalargin bound to poly (butyl cyanoacrylate) nanoparticles after IV injections to mice. Life Sci. 2000; 66(6): 495-502.

48. Veiseh O, Sun C, Fang C, Bhattarai N, Gunn J, Kievit F, et al. Specific targeting of brain tumors with an optical/magnetic resonance imaging nanoprobe across the blood-brain barrier. Cancer Res. 2009; 69(15): 6200-7.

49. Agyare EK, Curran GL, Ramakrishnan M, Caroline CY, Poduslo JF, Kandimalla KK. Development of a smart nano-vehicle to target cerebrovascular amyloid deposits and brain parenchymal plaques observed in Alzheimer's disease and cerebral amyloid angiopathy. Pharm Res. 2008; 25(11): 2674-84.

50. Monsalve Y, Tosi G, Ruozi B, Belletti D, Vilella A, Zoli M, et al. PEG-g-chitosan nanoparticles functionalized with the monoclonal antibody OX26 for brain drug targeting. Nanomedicine. 2015; 10(11): 1735-50.

51. Sun W, Xie C, Wang H, Hu Y. Specific role of polysorbate 80 coating on the targeting of nanoparticles to the brain. Biomaterials. 2004; 25(15): 3065-71.

52. Gulyaev AE, Gelperina SE, Skidan IN, Antropov AS, Kivman GY, Kreuter J. Significant transport of doxorubicin into the brain with polysorbate 80 -coated nanoparticles. Pharm Res. 1999; 16(10): 1564-9.

53. Wilson B, Samanta MK, Santhi K, Kumar KPS, Paramakrishnan N, Suresh B. Poly (n-butylcyanoacrylate) nanoparticles coated with polysorbate 80 for the targeted delivery of rivastigmine into the brain to treat Alzheimer's disease. Brain Res. 2008; 1200: 159-68.

54. Wilson B, Samanta MK, Santhi K, Kumar KPS, Paramakrishnan N, Suresh B. Targeted delivery of tacrine into the brain with polysorbate 80 -coated poly (n-butylcyanoacrylate) nanoparticles. Eur J Pharm Biopharm. 2008; 70(1): 75-84.

55. Feng B, Tomizawa K, Michiue H, Miyatake S-i, Han X-J, Fujimura A, et al. Delivery of sodium borocaptate to glioma cells using immunoliposome conjugated with anti-EGFR antibodies by ZZ-His. Biomaterials. 2009; 30(9): 1746-55.

56. Huwyler J, Wu D, Pardridge WM. Brain drug delivery of small molecules using immunoliposomes. Proc Natl Acad Sci U S A. 1996; 93(24): 14164-9.

57. Huwyler J, Yang J, Pardridge WM. Receptor mediated 
delivery of daunomycin using immunoliposomes: pharmacokinetics and tissue distribution in the rat. $\mathrm{J}$ Pharmacol Exp Ther. 1997; 282(3): 1541-6.

58. Schnyder A, Krähenbühl S, Drewe J, Huwyler J. Targeting of daunomycin using biotinylated immunoliposomes: pharmacokinetics, tissue distribution and in vitro pharmacological effects. J Drug Target. 2005; 13(5): 325-35.

59. Bondì ML, Craparo EF, Giammona G, Drago F. Braintargeted solid lipid nanoparticles containing riluzole: preparation, characterization and biodistribution. Nanomedicine. 2010; 5(1): 25-32.

60. Wu J, Wang C, Sun J, Xue Y. Neurotoxicity of silica nanoparticles: brain localization and dopaminergic neurons damage pathways. ACS nano. 2011; 5(6): 4476-89.

61. Ze Y, Zheng L, Zhao X, Gui S, Sang X, Su J, et al. Molecular mechanism of titanium dioxide nanoparticles-induced oxidative injury in the brain of mice. Chemosphere. 2013; 92(9): 1183-9.

62. Kumagai A, Eisenberg JB, Pardridge W. Absorptivemediated endocytosis of cationized albumin and a beta-endorphin-cationized albumin chimeric peptide by isolated brain capillaries. Model system of bloodbrain barrier transport. J Biol Chem. 1987; 262(31): 15214-9.

63. Hülsermann U, Hoffmann MM, Massing U, Fricker G. Uptake of apolipoprotein E fragment coupled liposomes by cultured brain microvessel endothelial cells and intact brain capillaries. J Drug Target. 2009; 17(8): 610-8.

64. Huang M, Hu M, Song Q, Song H, Huang J, Gu $\mathrm{X}$, et al. GM1-modified lipoprotein-like nanoparticle: multifunctional nanoplatform for the combination therapy of alzheimer's disease. ACS nano. 2015; 9(11): 10801-16.

65. Moos T, Nielsen TR, Skjørringe T, Morgan EH. Iron trafficking inside the brain. J Neurochem. 2007; 103(5): 1730-40.

66. De Boer A, Gaillard P. Drug targeting to the brain. Annu Rev Pharmacol Toxicol. 2007; 47: 323-55.
67. Bergen JM, Pun SH. Analysis of the intracellular barriers encountered by nonviral gene carriers in a model of spatially controlled delivery to neurons. J Gene Med. 2008; 10(2): 187-97.

68. De Boer A, Van Der Sandt I, Gaillard P. The role of drug transporters at the blood-brain barrier. Annu Rev Pharmacol Toxicol. 2003; 43(1): 629-56.

69. Sadekar S, Ghandehari H. Transepithelial transport and toxicity of PAMAM dendrimers: implications for oral drug delivery. Adv Drug Deliv Rev. 2012; 64(6): 571-88.

70. Kotzé AF, Lueßen HL, de Leeuw BJ, Verhoef JC, Junginger HE. Comparison of the effect of different chitosan salts and $\mathrm{N}$-trimethyl chitosan chloride on the permeability of intestinal epithelial cells (Caco-2). J Control Release. 1998; 51(1): 35-46.

71. Afergan E, Epstein H, Dahan R, Koroukhov N, Rohekar K, Danenberg HD, et al. Delivery of serotonin to the brain by monocytes following phagocytosis of liposomes. J Control Release. 2008; 132(2): 84-90.

72. Ali IU, Chen X. Penetrating the blood-brain barrier: promise of novel nanoplatforms and delivery vehicles. ACS Nano. 2015; 9(10): 9470-4.

73. Rahman M, Hoh B, Kohler N, Dunbar EM, Murad GJ. The future of glioma treatment: stem cells, nanotechnology and personalized medicine. Future Oncol. 2012; 8(9): 1149-56.

74. Liu L, Eckert MA, Riazifar H, Kang D-K, Agalliu D, Zhao W. From blood to the brain: can systemically transplanted mesenchymal stem cells cross the blood-brain barrier? Stem Cells Int. 2013; 7. doi: 10.1155/2013/435093.

75. Pietroiusti A, Campagnolo L, Fadeel B. Interactions of engineered nanoparticles with organs protected by internal biological barriers. Small. 2013; 9(9-10): 1557-72.

76. Landsiedel R, Fabian E, Ma-Hock L, Wohlleben W, Wiench K, Oesch F, et al. Toxico-/biokinetics of nanomaterials. Arch Toxicol. 2012; 86(7): 1021-60. 